\title{
As estratégias de relacionamento das operadoras de telefonia celular: uma investigação comparativa entre clientes pré-pagos e pós-pagos em Belém do Pará, Brasil
}

\author{
Patrícia Helena Martins Nazareth Administradora, Universidade Federal do Pará (UFPa). Pós-graduanda em Gestão Empresarial pela Universidade da Amazônia \\ (UNAMA) - Brasil. patrícia_nazareth@hotmail.com. \\ Carlos André Corrêa de Mattos Doutor em Ciências Agrárias pela Universidade Federal da Amazônia (UFRA). Mestre em Gestão e Desenvolvimento Regional. \\ Professor da Universidade Federal do Pará (UFPA) - Brasil. carlosacmattos@hotmail.com.
}

\begin{abstract}
RESUMO
O setor de telefonia móvel tem elevada representatividade no mercado brasileiro, mas, ao mesmo tempo, é alvo de críticas constantes dos usuários do serviço. $O$ presente artigo tem como objetivo apresentar os resultados do desempenho das operadoras de telefonia móvel, avaliado por clientes de planos pré-pagos e pós-pagos, da cidade de Belém-Pa. A pesquisa utilizou a abordagem quantitativa, e teve caráter exploratório, descritivo e ex-post facto. Foram aplicados 405 questionários aos usuários dos serviços de telefonia móvel, selecionados em amostra probabilística aleatória simples e utilizadas técnicas de estatística descritiva e não paramétrica (Mann-Whitney) para tratar os dados. Os resultados indicaram que o grupo pós-pago demonstra uma insatisfação um pouco menor com os serviços de telefonia. Contudo, de modo geral, tanto os clientes das modalidades pré-pagos quanto os pós-pagos, avaliam negativamente os serviços prestados pelas operadoras de telefonia móvel.
\end{abstract}

Palavras-chave: Telefonia Móvel. Usuários. Serviço Pré-Pago. Serviço Pós-Pago.

\section{Relationship strategies of mobile operators: a comparative investigation between prepaid and postpaid customers in Belém - Pará, Brazil}

\begin{abstract}
The mobile phone industry has high participation in the Brazilian market, but at the same time, it is the target of constant criticism from users of the service. This article aims to present the results about the performance of mobile operators, rated by customers of pre-paid and post-paid services, in Belem, Pará. The research used the quantitative approach, and was of exploratory, descriptive, and ex-post facto character. Four hundred and five (405) questionnaires were applied to users of mobile services, selected in simple random probability sample and techniques used descriptive statistics and non-parametric (Mann-Whitney) to process the data. The results indicated that the post-paid group shows a slightly lower dissatisfaction with telephone services. However, in general both, customers of prepaid and postpaid modality, evaluate the services provided by mobile operators negatively.
\end{abstract}

Keywords: Mobile. Users. Prepaid service. Post Paid Service. 


\section{INTRODUÇÃO}

O setor de serviços, que é responsável por mais da metade do Produto Interno Bruto (PIB) brasileiro, é o principal destino dos investimentos estrangeiros diretos no país. Este segmento, além de ser o maior gerador de empregos para a população brasileira, assume também um papel cada vez mais importante no desenvolvimento da economia mundial (ADVFN BRASIL, 2015; IBGE, 2015), uma vez que, em todo o mundo, observa-se uma crescente prevalência de economias voltadas para o setor de serviços (ZEITHAML; BITNER; GREMLER, 2014; FITZSIMMONS; FITZSIMMONS, 2014). Nesse cenário, as empresas de telecomunicações assumem expressiva parcela do setor, inclusive no mercado brasileiro onde são responsáveis por $5 \%$ do PIB (TELEBRASIL, 2014).

Segundo os dados da Associação Brasileira de Telecomunicações, o Brasil tem a quinta maior rede de telecomunicações do mundo, sendo o oitavo maior mercado de tecnologia da informação e comunicação, o quarto em número de aparelhos celulares, e o sexto mais competitivo no ramo da telefonia móvel - além de ser o maior da América Latina neste segmento (TELEBRASIL, 2014). Por outro lado, de acordo com o levantamento da Secretaria Nacional do Consumidor, o serviço de telefonia móvel liderou o ranking de reclamações em 2015, em todos os PROCONS do país (SENACON, 2015).

Em mercados competitivos, como no caso da telefonia móvel, o investimento na qualidade do serviço, possibilita alcançar o sucesso almejado. A diversidade de serviços de qualidade pode gerar aumento na participação do mercado e, em última instância, significa a diferença entre o sucesso e o fracasso financeiro da organização. Há evidências de que a oferta de qualidade resulta em compras repetidas, assim como contribui para obtenção de novos clientes (HOFFMAN et al, 2009; BOONE; KURTZ, 2011).

Outro aspecto essencial para solidificar as empresas em ambientes de alta competitividade, é a busca pela fidelização dos clientes. Apesar dessa estratégia representar um desafio especialmente em mercados de commodities, como é o caso da telefonia móvel, a satisfação dos consumidores deve ser percebida claramente, a partir do atendimento de suas expectativas por meio da entrega de valor.

A oferta de valor é uma forma especial para satisfazer o cliente, pois vai ao encontro de suas expectativas, o que aumenta a probabilidade de que ele continue consumindo, e mantenha-se fiel à empresa por muito tempo. Para fidelizar é preciso, antes de tudo, identificar as necessidades, preocupações, formas de uso e outros aspectos, que os clientes consideram como valor e com base neles, desenvolver produtos e serviços que conduzam à elevada satisfação (COBRA, 2009; GOUVÊA, 2005).

Tendo como base o desempenho das operadoras de telefonia móvel quanto à satisfação, imagem institucional, fidelidade e relacionamento, avaliados pelos clientes de planos pré-pagos e pós-pagos, o presente artigo tem por objetivo avaliar esses aspectos nas operadoras de telefonia móvel na cidade de Belém do Pará. Assim, procura-se responder as seguintes questões de pesquisa: (1) qual é a avaliação dos clientes de empresas de telefonia móvel, quanto à satisfação, imagem institucional, relacionamento e fidelidade com as empresas prestadoras de serviços? (2) existem diferenças nesses aspectos entre clientes que optaram pelas modalidades pré-paga e pós-paga?

Com esse propósito, o estudo utilizou como estratégia de investigação a pesquisa de campo, com 405 entrevistados selecionados em amostra probabilística aleatória simples, e tratamento de dados realizado com estatística descritiva e não paramétrica (Mann-Whitney), técnicas selecionadas ora para descrever os resultados, ora para testar a hipótese que norteia esse estudo e estrutura-se na compreensão que, em oferta de serviços semelhantes, não se espera que ocorram diferenças significativas entre os dois grupos investigados.

\section{TELECOMUNICAÇÕES: O SERVIÇO DE TELEFONIA MÓVEL NO BRASIL}

Serviços de telecomunicações são definidos como a "transmissão, emissão ou recepção de símbolos, caracteres, sinais, escritos, imagens, sons, ou informações de qualquer natureza, por fio, rádio, eletricidade, meios ópticos, ou qualquer outro processo eletromagnético" (TELEBRASIL, 2014). De acordo com a Associação Brasileira de Telecomunicações, a prestação desses serviços é realizada por agentes que detenham concessão, permissão, ou autorização para prestá-los e fazem parte desse segmento, os Serviços de Comunicação Móvel, caracterizados pela mobilidade do usuário.

A Telefonia Celular é o principal serviço de Comunicação Móvel, prestado no Brasil por detentores de autorização de Serviço Móvel Pessoal (SMP). Existem até cinco empresas autorizadas prestando esse serviço em cada região do país, consolidadas nos seguintes grupos: Vivo, Claro, Tim, Oi, CTBC, Sercomtel e Nextel. Além desses grupos, há ainda, as prestadoras de rede virtual (MVNO), regulamentadas pela Anatel em 2010 (TELEBRASIL, 2014). 
A operacionalização da telefonia móvel no Brasil teve início em 1990, no estado do Rio de Janeiro, com a Telerj Celular - Telecomunicações do Estado do Rio de Janeiro. Em março de 2016, o Brasil registrou 257,81 milhões de linhas ativas na telefonia móvel, o que ultrapassa o total da população brasileira, sendo que $71,41 \%$ dessas linhas são referentes a planos pré-pagos, e 28,59\% a pós-pagos. Entre as principais concorrentes, a Vivo está na liderança, obtendo $28,42 \%$ de participação no setor, contra $26,09 \%$ da Tim, 25,32\% da Claro e 18,52\% da Oi (ANATEL, 2016).

Todo este contexto impõe desafios poderosos a serem superados, principalmente na área de qualidade dos serviços oferecidos pelas operadoras. Entre as principais concorrentes no setor, a Tim liderou o ranking das reclamações de telefonia celular em 2014, sendo responsável por 29,5\% das reclamações, seguida por $26,14 \%$ da Vivo, $22,5 \%$ da Claro, e 21,6\% da Oi. Do total de reclamações por serviço recebidas pela Anatel, entre janeiro e dezembro de 2014, 41\% foram referentes aos serviços de telefonia móvel (ANATEL, 2016).

Na última edição do Estudo de Aquisição e Retenção, realizado em 2014 pela Nokia Siemens Networks, foi demonstrado que o consumidor brasileiro valoriza a qualidade do serviço e a cobertura da rede, como os principais fatores para permanecer ou trocar de operadora, sendo esses os maiores responsáveis pela retenção de $41 \%$ dos clientes. Já a categoria de preço e cobrança - que inclui custos de aparelhos, voz, internet, entre outros - foi apontada como a mais importante, por $33 \%$ dos usuários.

Os resultados da pesquisa demonstram a exigência na qualidade e o aumento da portabilidade, por parte dos consumidores brasileiros (NOKIA-SIEMENS NETWORKS, 2014). Segundo o relatório da Associação Brasileira de Recursos em Telecomunicações, ABR TELECOM, desde setembro de 2008 - quando a portabilidade numérica foi implantada gradativamente - até o dia 30 de setembro de 2015, foram efetivadas 18,10 milhões de migrações por usuários de terminais móveis (ABRTELECOM, 2015).

\section{GESTÃO DE SERVIÇOS: CARACTERÍSTICAS E QUALIDADE DOS SERVIÇOS}

Kotler, Hayes e Bloom (2002) destacam algumas características de serviços, iniciando pela intangibilidade que, significa que serviços não são provados, palpáveis ou avaliados previamente, e na verdade são avaliados a partir de impressões ou conceitos. Assim, o profissional responsável pelo serviço, deve ser capaz de: oferecer uma reputação reconhecida, sobre os processos e os resultados esperados pelo serviço prestado; compreender que os serviços são indivisíveis, pois eles não podem ser separados dos prestadores, portanto, ambos acabam por influenciar na avaliação da qualidade da oferta; reconhecer a possibilidade de variabilidade, uma vez que, como o cliente tem papel preponderante na prestação de serviços, a experiência com o recebimento dos serviços varia de cliente para cliente. Portanto, a qualidade dos serviços prestados também pode ser modificada a cada oferta, dificultando a padronização e, por conseguinte, propiciando maior variabilidade; ter ciência que serviços são altamente perecíveis, o que significa que os serviços não podem ser armazenados para a venda, ou utilização posterior.

Esses aspectos dificultam a promoção do equilíbrio entre oferta e demanda, tornando essa peculiaridade um desafio a mais na gestão de serviços. Observa-se que, diferentemente dos produtos, a presença ou a possibilidade de formação de estoques contribui para superar esse impasse (HOFFMAN et al, 2009; ZEITHAML; BITNER; GREMLER 2014; KOTLER; KELLER, 2006; LOVELOCK; WRIGHT, 2003).

Ao se referirem à qualidade em serviços, Zeithaml, Bitner e Gremler (2014) destacam que os consumidores julgam a qualidade, levando em consideração diversos fatores de ordem emocional e racional e são induzidos por cinco dimensões, condutoras da qualidade percebida em serviços. As dimensões propostas por Parasuraman, Zeithaml e Berry (1985) foram identificadas como uma alternativa para as organizações acompanharem a qualidade que é entregue aos clientes, e deram origem ao Modelo Servqual. A partir dessa compreensão constituíram-se as dimensões: (1) Confiabilidade: capacidade de executar o serviço prometido de forma confiável e precisa; (2) Capacidade de resposta: disposição de ajudar os clientes e fornecer o serviço imediatamente; (3) Segurança: é o conhecimento e a cortesia dos funcionários, e sua capacidade de inspirar confiança e certeza; (4) Empatia: é a atenção individualizada dispensada aos clientes; (5) Elementos tangíveis: constituem a aparência das instalações físicas, dos equipamentos, dos funcionários, e dos materiais de comunicação (FITZSIMMONS; FITZSIMMONS, 2014; CORRÊA; CAON, 2008; JOHNSTON, 1995; GHOBADIAN; SPELLER; JONES, 1994; GIANESI; CORRÊA, 1994; PARASURAMAN; ZEITHAML; BERRY, 1985; LOVELOCK; WRIGHT, 2003).

O modelo Desempenho-Atitude-Comportamento, desenvolvido por Kotler, Hayes e Bloom (2002) complementa ao identificar três tipos de reações dos clientes ao entrarem em contato com um serviço: (1) o cliente observa um desempenho muito melhor que o esperado, fica encantado e provavelmente será leal à empresa; (2) o desempenho percebido é conforme o esperado, o cliente fica satisfeito, mas suas expectativas não são superadas - 
o cliente não está encantado como no primeiro caso - o que resultará em um comportamento vulnerável em relação à empresa, se posicionado de forma mais acessível às ofertas da concorrência; (3) observa um rendimento pior que o esperado, fica insatisfeito e a empresa irá perdê-lo.

\section{MARKETING DE RELACIONAMENTO}

O mundo mudou muito desde que a palavra marketing foi utilizada pela primeira vez, nos Estados Unidos da América do Norte, em 1902. Desde então, o marketing constitui-se enquanto teoria, fato que possibilitou sua inserção no campo do conhecimento humano (AJZENTAL, 2010). Atualmente, os consumidores escolhem a partir de uma enorme variedade de ofertas, como nunca visto antes na humanidade. Os produtos, que no passado só incluíam uma ou duas categorias, agora estão presentes em muitas formas diferentes. Os profissionais de marketing tentam influenciar nas escolhas dos consumidores durante o processo de compra, fornecendo informações persuasivas sobre suas ofertas em formatos úteis e os mais convenientes possíveis, para o consumidor (BOONE; KURTZ, 2011; ZEITHAML; BITNER; GREMLER, 2014).

Para Kotler e Keller (2006, p. 139) "com a ascensão de tecnologias digitais como a internet, os consumidores de hoje, cada vez mais informados, esperam que as empresas façam mais do que se conectar com eles, mais do que satisfazê-los e até mais do que encantá-los". Em um mundo, onde o cliente tem tantas opções, a criação de vínculos fortes e duradouros é uma tarefa difícil de executar. Dessa forma, o marketing de relacionamento torna-se uma ferramenta fundamental, para ajudar na construção de vínculos empresariais mais sólidos, entre comprador e vendedor.

O marketing de relacionamento tem como meta principal construir relações de longo prazo e mutuamente satisfatórias. Essa convivência possui elementos chaves como clientes, fornecedores, funcionários, distribuidores e outros stakeholders de marketing, cujo objetivo é conquistar ou reter negócios com eles. Ela visa construir fortes ligações econômicas, técnicas, e sociais entre as partes envolvidas (KOTLER; KELLER, 2006; COBRA, 2009; ZEITHAML; BITNER; GREMLER, 2014; BOONE; KURTZ, 2011; MCKENNA, 1997; GRÖNROOS, 1997).

Este segmento do marketing se estrutura a partir de um conjunto de aspectos que são bem específicos, assim: (1) procura criar valor e compartilhar esse valor entre o produtor e o consumidor; (2) reconhece o papel fundamental que os clientes individuais têm, na definição do valor que desejam. Nessa perspectiva, o cliente ajuda a empresa a fornecer um pacote de benefícios que ele valoriza. $O$ valor passa a ser criado de forma compartilhada, não apenas oferecido unilateralmente; (3) a estratégia de marketing, e seu foco no cliente, exige um processo de planejamento e alinhamento na negociação, nas políticas de comunicação, na tecnologia e no pessoal, para manter o valor que o cliente individual deseja; (4) representa esforço contínuo e colaborativo, entre o comprador e o vendedor, desse modo, funciona em tempo real; (5) reconhece o valor dos clientes por seu período de vida de consumo. Ao reconhecer o valor do período de vida, o marketing de relacionamento procura unir progressivamente a empresa aos clientes, distanciando-se da transação no sentido de uma venda isolada; (6) procura construir uma cadeia de relacionamento dentro da organização, para criar o valor desejado pelos clientes (OBOREH; OGECHUKWU; FRANCIS, 2011; MONTEIRO, 2003; GORDON, 1999).

\section{IMAGEM INSTITUCIONAL: A MARCA E O COMPORTAMENTO DO CONSUMIDOR}

De acordo com Las Casas (2001), a imagem é o resultado da soma de impressões mentais - que podem ser afetivas ou racionais - provenientes de sentimentos, crenças, atitudes e informações criadas pelas pessoas e que são relacionadas a empresas ou instituições. Essas impressões podem gerar atributos positivos ou negativos, que constituirão as características da respectiva imagem. Em relação a essas características, Tavares (1998) cita que a imagem pode ser percebida como a possuidora de atributos únicos sobre uma marca, que as diferenciam das concorrentes. Esse efeito é resultado das ações de marketing, que trabalham nos consumidores as percepções formadas sobre a marca, e que são retidas na memória.

Na obra de Dobni e Zinkhan (1990) é possível observar alguns conceitos codificados referentes à definição de imagem, que tem por finalidade identificar as principais semelhanças e variações, que existem na conceituação entre diversos autores (Quadro 1). 
Quadro 1- Conceituação de Imagem

\begin{tabular}{|c|c|}
\hline Autor & Conceituação \\
\hline Gardner e Levy (1955) & $\begin{array}{l}\text { Ênfase em elementos cognitivos ou psicológicos: sentimentos, atitudes e ideias do } \\
\text { consumidor, em relação a uma marca. }\end{array}$ \\
\hline Herzog (1973) & $\begin{array}{l}\text { Soma total das impressões que o consumidor recebe de várias fontes. Todas essas } \\
\text { impressões equivalem a uma espécie de personalidade da marca, que é semelhante para } \\
\text { o público consumidor em geral, embora alguns grupos específicos também possam ter } \\
\text { atitudes diversificadas. }\end{array}$ \\
\hline Reynolds (1965) & $\begin{array}{l}\text { Construto mental desenvolvido pelo consumidor com base em poucas impressões - } \\
\text { selecionadas dentre a grande quantidade de impressões disponíveis - que passam a } \\
\text { existir através de um processo criativo, em que as impressões selecionadas são } \\
\text { elaboradas, enfeitadas e ordenadas. }\end{array}$ \\
\hline Levy e Glick (1973) & $\begin{array}{l}\text { Mistura de noções e desilusões, baseados em vários aspectos. Na maior parte do tempo } \\
\text { as imagens são de fato ilusões. A imagem também é uma interpretação, um conjunto de } \\
\text { inferências e reações, com relação a um símbolo. Não é o objeto em si, porém refere-se a } \\
\text { ele. }\end{array}$ \\
\hline Levy (1978) & $\begin{array}{l}\text { É uma constelação de imagens e ideias na mente das pessoas, que resumem o } \\
\text { conhecimento da marca, e suas principais atitudes em relação a ela. }\end{array}$ \\
\hline Bullmore (1984) & $\begin{array}{l}\text { É o que as pessoas pensam e sentem sobre ela. Esses pensamentos e sentimentos não } \\
\text { vão, e não podem ser universalmente idênticos. A imagem está na mente de quem vê, e } \\
\text { é condicionada pela natureza do próprio objeto. }\end{array}$ \\
\hline $\begin{array}{l}\text { Reynolds e Gutman } \\
\text { (1984) }\end{array}$ & $\begin{array}{l}\text { Conceitos armazenados na memória das pessoas, que diferenciam um produto de uma } \\
\text { empresa de seus concorrentes. Corresponde à síntese dos atributos do produto, valores } \\
\text { pessoais, significados sociais, e consequências para o consumidor. }\end{array}$ \\
\hline
\end{tabular}

Fonte: Adaptado de Dobni e Zinkhan (1990).

Marca pode ser conceituada como qualquer nome, ou símbolo distintivo, que tenha por finalidade determinar a origem de produtos e serviços de um vendedor específico, ou um conjunto deles. As marcas têm por finalidade diferenciar os produtos ou serviços de seus concorrentes. Mas, principalmente, o de reduzir a possibilidade de os produtos tornarem-se commodities (COOPER; ARGYRIS, 2003; MATTOS et al, 2013). As marcas podem representar confiabilidade, prestígio, durabilidade, qualidade, entre outras (HOOLEY; PIERCY; NICOLAUD, 2011).

Ao considerar o comportamento dos clientes, os aspectos tangíveis são facilmente percebidos durante o processo de decisão de compra, especialmente quando são considerados em âmbito de produtos. Contudo, os aspectos mais abstratos, imateriais, ou intangíveis, são questões fundamentais, que devem ser consideradas para a conquista de posições competitivas no mercado. Dentre elas estão as marcas, que possuem valor próprio, em decorrência de sua capacidade de conferir valor tanto a produtos, quanto a serviços. Marcas reconhecidas exprimem a reputação ou a imagem da organização, e devem ser facilmente identificáveis (HOOLEY; PIERCY; NICOLAUD, 2011).

\section{FIDELIDADE E SATISFAÇÃO DOS CLIENTES}

Fidelidade à marca é a intensidade com que o consumidor mantém uma atitude positiva, em relação à organização que a possui. Esse comportamento origina-se a partir da criação de uma relação de confiança e satisfação, que ele pretende continuar no futuro. Fidelização está diretamente relacionada com a satisfação - ou insatisfação - com a organização e isso pode ser acumulado ao longo do tempo, constituindo-se com base no que é percebido da qualidade do produto, ou de outros aspectos subjetivos da relação de consumo (WARD; DAGGER, 2007). Essa constatação leva a organização considerar mais barato manter clientes antigos, do que conquistar novos. Portanto, as empresas devem dar prioridade máxima à criação de estratégias, que contribuam para manter a fidelidade à marca (AMARAL; DANTAS, 2008). 
De acordo com Zeithaml, Bitner e Gremler (2014), a fidelidade do cliente pode cair subitamente quando ele atinge certo nível de insatisfação, o que ocorre com atributos essenciais do serviço. As ações da concorrência, especialmente na publicidade e na promoção de vendas, também podem influenciar negativamente na fidelidade dos consumidores. Nesse aspecto, elevar as barreiras de saída, representa uma estratégia interessante para compreender a longevidade nas relações com os clientes. Além disso, é claro, há a necessidade de melhorar a gestão para se obter um relacionamento eficiente, que é um fator relevante considerado pelos consumidores, diante das ofertas da concorrência.

As empresas progressivamente percebem que, níveis crescentes de satisfação, podem estar associados a maior fidelidade e aos lucros da companhia (ZEITHAML; BITNER; GREMLER, 2014). Clientes satisfeitos adquirem produtos com mais frequência e a possibilidade de perdê-los para concorrentes é menor. Empresas com altos índices de satisfação parecem ter maior capacidade de isolar-se das pressões competitivas, principalmente as relacionadas com preços. Na maioria das vezes, os clientes preferem pagar mais e permanecer em uma empresa que satisfaça seus desejos, a assumir o risco de mudar para outra com uma oferta de preço mais baixo (HOFFMAN et al, 2009).

Mattos et al (2013, p. 44) destacam que "a satisfação dos clientes é, provavelmente, o mais tradicional indicador que as escolhas organizacionais foram acertadas". Para Kotler e Keller (2006) a satisfação deriva do confronto entre o que o comprador espera, e a performance observada em um produto. Se a performance não atende as expectativas, o cliente ficará insatisfeito, porém, se as expectativas forem confirmadas, ele ficará satisfeito. Logo, se o resultado superar as expectativas, o cliente ficará altamente satisfeito ou encantado (COBRA, 2009; ZEITHAML; BITNER; GREMLER, 2014; HOFFMAN et al, 2009; FITZSIMMONS; FITZSIMMONS, 2014; GIANESI; CORRÊA, 1994).

$\mathrm{Na}$ visão de Kotler, Hayes e Bloom (2002, p. 44) "os clientes que recebem o que desejam tendem a ficar satisfeitos; não obstante, existem certas indicações de que até mesmo o cliente satisfeito pode procurar outro prestador de serviço". Os mesmos autores referem-se ao "Índice do Cliente Cativo", desenvolvido pela Burke Customer Satisfaction Associates e criado para medir a relação de lealdade do cliente. O índice considera essencialmente três dimensões: (1) a satisfação geral com a empresa; (2) a probabilidade de continuar realizando negócios com a empresa; (3) a probabilidade de recomendar a empresa a terceiros. Caso o cliente não atribua à empresa a melhor classificação possível em algum, ou em todos os critérios, o risco de trocar a empresa por outra se torna muito elevado.

\section{METODOLOGIA}

Integraram o universo do estudo os clientes das quatro operadoras no estado Oi, Vivo Claro e Tim. A amostra classificada como probabilística aleatória simples, foi calculada com $95 \%$ de margem de segurança e 4,8\% de erro máximo admitido. A pesquisa de campo foi composta por 285 (n1) clientes de serviço pré-pago e 120 (n2) pós-pago, totalizando 405 (n) questionários válidos. Para o cálculo da amostra, foi utilizada a equação 1, conforme Pinheiro et al (2009):

$$
n=\left(0,25 * Z^{2}\right) /\left(e^{2}\right)
$$

Em que: $n=$ tamanho da amostra; $Z=$ desvio-padrão relacionado ao índice de confiança; e=erro amostral admitido.

A pesquisa de campo, segundo Gil $(2008$, p. 55) "se caracteriza pela interrogação direta das pessoas, cujo comportamento se deseja conhecer" ocorreu durante o mês de agosto de 2015, na cidade de Belém do Pará. O instrumento de coleta de dados foi o questionário, adaptado de Nespolo (2014) e utilizou a escala intervalar de Likert para mensurar a intensidade das respostas, a escala contou com sete opções de resposta, estendendo-se de 1 (um) para discordo totalmente, até 7 (sete) para concordo totalmente.

As interpretações das respostas foram divididas em três categorias: a primeira, com avaliação entre 1 (um) e 3 (três), foi considerada discordante; a segunda, com avaliação 4 (quatro), posicionada no ponto central da escala, foi interpretada como indiferente, visto que não há concordância, nem discordância; e a terceira, com avaliação entre 5 (cinco) e 7 (sete), foi classificada como concordante.

A classificação da pesquisa foi descritiva, uma vez que os fatos são estudados através de técnicas para descobrir a frequência, a natureza, as características e conexões com outros fenômenos, e tem como finalidade analisar, registrar, observar, descrever, e estabelecer relações entre as variáveis (CERVO; BERVIAN, 1983). A investigação também assumiu caráter exploratório, pois visa proporcionar aproximação inicial do fenômeno, conhecê-lo melhor, torná-lo mais explícito e possibilitar a formulação de hipóteses. Quanto à ocorrência, a pesquisa caracteriza-se como um estudo ex-post facto, ou seja, as variáveis foram estudadas após a manifestação do 
fenômeno. Para a análise das variáveis foi utilizada a abordagem quantitativa, na qual os dados podem ser codificados e analisados, através de técnicas e recursos estatísticos (GIL, 2008).

No tratamento de dados foram selecionadas duas técnicas estatísticas: a descritiva, para realizar a distribuição de frequência e assim mostrar as características gerais do fenômeno e o perfil dos entrevistados; e a não paramétrica, por meio do teste de Mann-Whitney (U), selecionado para identificar a presença, ou não, de diferença entre os grupos investigados. Este teste não paramétrico foi escolhido por atender a três pré-requisitos de adequação: (1) a presença de dois grupos investigados, aleatoriamente desenhados a partir da população alvo, o que implica a ausência de erros de medição e de amostragem; (2) cada medida ou observação correspondeu a um participante diferente. Em termos estatísticos, caracteriza-se a independência entre os grupos e, portanto, independência da amostra; (3) a utilização de variáveis com escala de medida ordinal (NACHAR, 2008).

A fim de atender o objetivo proposto no trabalho, a hipótese de pesquisa foi formulada como:

$\mathrm{H}_{0}$ : Os clientes de planos pré-pagos e pós-pagos avaliam igualmente os serviços prestados pelas operadoras de telefonia móvel quanto à satisfação, imagem institucional, fidelidade e relacionamento.

O estudo utilizou o $\mathrm{p}$-valor para determinar as diferenças entre grupos e para tanto, a regra de decisão para rejeitar $\mathrm{HO}$ constituiu-se da seguinte forma: se o $\mathrm{p}$-valor for inferior ou equivalente a a (sig. $\leq 0,05)$, rejeita-se $\mathrm{H} 0$ e por conseguinte não é possível afirmar que exista igualdade entre as avaliações dos dois grupos de clientes, pré-pago e pós-pago; entretanto, caso o p-valor seja superior a a (sig. > 0,05), deve-se aceitar $\mathrm{H} 0$ e considerar que as eventuais diferenças nas respostas ocorreram ao acaso.

Validade e confiabilidade também são dois elementos fundamentais na avaliação de um instrumento de medição. Neste estudo, o Alfa de Cronbach foi utilizado para medir a consistência interna do instrumento e assim garantir a sua validade. Mattos et al (2015) afirmam que há diferentes relatos sobre os valores aceitáveis de alfa, que variam a partir de 0,600 e 0,700. Um valor baixo para o alfa pode ser devido a um baixo número de questões, má interrelação entre os itens, ou construções heterogêneas. Por outro lado, se o coeficiente alfa for muito elevado, pode sugerir que alguns itens são redundantes (TAVAKOL; DENNICK, 2011). No presente estudo, o Alfa de Cronbach foi de 0,920 evidenciando elevada consistência interna.

\section{APRESENTAÇÃO DE RESULTADOS}

O resultado do tratamento de dados revelou que os entrevistados foram predominantemente do gênero masculino, com 55,06\% (223) entre os 405 casos pesquisados. Quanto à idade, os estratos mais frequentes foram entre 26 a 35 anos, representando 33,08\% (134) da amostra, seguida da faixa entre 15 a 25 anos, com 31,35\% (127) dos participantes posicionados nessa categoria.

O tempo como cliente na operadora foi entre 1 a 5 anos, com 50,86\% (206) da amostra, seguido de 6 a 10 anos correspondente a $41,23 \%$ (167) das respostas. Sobre a utilização da Internet fornecida pelas operadoras $84,2 \%$ (341) afirmaram que utilizam esse serviço, enquanto $15,8 \%$ (64) não fazem uso desta função. Verificou-se um equilíbrio entre as respostas sobre o uso de outras operadoras de telefonia móvel, sendo 50,12\% (203) usuários de serviços de mais de uma operadora, enquanto que $49,88 \%$ (202) declararam utilizar apenas um serviço. Merece destaque que, ao avaliarem os serviços, os entrevistados foram instruídos a avaliarem sua operadora principal. Do total de entrevistados, $70,37 \%$ (285) eram clientes de serviço pré-pago, e 29,63\% (120) mantinham contratos póspagos.

A avaliação geral da atuação das operadoras de telefonia quanto à satisfação, imagem institucional, fidelidade e, por conseguinte, relacionamento (Tabela 1), revelou que tanto os clientes que firmaram contratos prépagos, quanto àqueles que optaram pelos contratos do tipo pós-pagos, avaliam de forma negativa a relação de consumo com as operadoras de telefonia móvel. Essa constatação decorre do elevado percentual de respostas nas faixas inferiores da escala, predominante entre as variáveis em estudo, e em ambos os grupos investigados (Tabela 01). O resultado indica que as estratégias escolhidas pelas empresas não conseguem gerar um valor suficiente junto aos clientes, para construir uma imagem positiva e possibilitar um processo de fidelização, que advém eminentemente de um desempenho superior (KOTLER; HAYES; BLOOM, 2002).

Essa situação deve ser tratada com atenção pelas empresas, consumidores, órgãos de defesa do consumidor e agências reguladoras, especialmente, ao se considerar a importância do setor de serviços para a economia brasileira e, principalmente, por se tratar de um segmento consolidado, como é o caso das empresas de telefonia móvel. Destaca-se que, como identificaram Mattos et al (2013), os consumidores de serviços de telefonia móvel são exigentes, o que reforça a necessidade de oferecer serviços de qualidade superior. 
Contudo, a comparação entre os dois grupos - pré e pós-pago - evidencia que a insatisfação, apesar de presente em ambos os grupos, é menor entre os clientes pós-pagos. Observa-se que, mesmo em commodities, como é o caso dos serviços de telefonia, os fornecedores desses serviços adotam estratégias diferenciadas para os clientes que apresentam um relacionamento mais estável com a empresa. Desta forma, mesmo insatisfeitos, esse estrato foi o que apresentou menores percentuais de insatisfação.

Assim, os clientes que mantêm contratos pré-pagos consideram que as empresas não demostram preocupação (V01) com eles (75\%), opinião compartilhada pelos que operam com contratos pós-pagos, porém com menor intensidade $(60 \%, \mathrm{p}$-valor 0,00$)$. Da mesma forma, ambos concordam que as operadoras não cumprem as promessas (V02, 66\% vs. $55 \%$, p-valor 0,00) e não acreditam que a maioria das pessoas desejaria fazer negócios com as operadoras de telefonia móvel (V03, 64\% vs.53\%, p-valor 0,00).

Quanto à credibilidade das informações recebidas pelos clientes das operadoras, a maioria dos consumidores não acredita nelas (V04,66\% vs. $47 \%$, p-valor 0,00), da mesma forma como apresentam restrições quanto à integridade do relacionamento por parte desses fornecedores (V05, 59\% vs. 48\%, p-valor 0,00). Esses aspectos são especialmente graves, pois, a impossibilidade de avaliar previamente os serviços, eleva a insegurança do consumidor e se dificulta o processo de decisão de compra (NÓBREGA, 2013; PALADINI; BRIDI, 2013; FITZSIMMONS; FITZSIMMONS, 2014).

A baixa confiabilidade, associada com as demais avaliações negativas, contribuem para que a maioria dos entrevistados não recomende a operadora para outros clientes (V06), situação observada em 68\% (194) dos clientes pré-pagos e $48 \%$ (58) dos pós-pagos ( $p$-valor 0,00 ). Semelhantemente, nenhum dos dois grupos pretende, em futuro próximo, demandar por serviços adicionais das empresas, pois, de acordo com as variáveis, a maior resistência ocorre entre os clientes pré-pagos (V07, 68\% vs. 60\%, p-valor 0,00). Essa constatação representa uma ameaça para as empresas, pois a demanda por serviços adicionais, além de melhorar o desempenho financeiro da organização, é um sinal que ela consegue atuar eficientemente em âmbito operacional (PALADINI; BRIDI, 2013).

A baixa diversidade que ocorre tipicamente em mercados de commodities, como é o caso dos serviços de telefonia móvel, eleva a necessidade de economia de escala, pois a homogeneidade de tecnologias e de mercados torna os produtos e serviços pouco diferenciados (SHETH, 1985). Quando essa situação se apresenta associada com a insatisfação dos consumidores, há maior sensibilidade aos preços, o que resulta na grande possibilidade de substituição do prestador (V08, 76\% vs. $63 \%$, p-valor 0,00 ). Esse aspecto torna os clientes mais sensíveis às promoções dos concorrentes (V13), situação verificada em 49\% (140) dos clientes pré-pagos. Os grupos divergiram mais fortemente nessa variável, pois os clientes pós-pagos revelaram-se menos suscetíveis às promoções dos concorrentes. Notou-se que $45 \%$ (48) discordam de que um preço menor, ou um desconto maior, sejam suficientes para substituir o prestador do serviço ( $p$-valor 0,00 ). Essa dimensão fortalece a necessidade de aumentarem os esforços na oferta do serviço, para captar clientes pós-pagos.

Quanto à manutenção do relacionamento, observa-se que o tempo e esforço empreendido para a substituição da operadora foram avaliados diferentemente entre os grupos (V09, 57\% vs. 37\%, p-valor 0,00), uma vez que os clientes pré-pagos percebem menor esforço do que os pós-pagos para a substituição do prestador de serviços. Essa compreensão, provavelmente decorre da maior simplicidade em substituir o chip do aparelho, do que realizar o distrato com a operadora. Desta forma, mesmo com a facilidade de migração garantida pela legislação e uma provável maior receptividade por parte das operadoras concorrentes de clientes pós-pagos, percebe-se que a regulamentação, materializada nos contratos de prestações de serviços pós-pagos, além de formalizarem a relação entre as partes, aumentam as barreiras de saída (PORTER, 2009).

Apesar dos grupos também divergirem quanto às precauções necessárias para realizarem negócios com as operadoras (V11,38\% vs. 47\%, p-valor 0,07) o p-valor não permitiu rejeitar H0. Portanto, aceita-se que não há diferenças significativas nos postos das respostas entre os grupos e que as diferenças de percentuais observadas ocorreram ao acaso. Comportamento semelhante ocorreu com outras variáveis, como a que avaliou a reputação das operadoras, que apesar das diversas percepções negativas em outras variáveis em estudo, a reputação das operadoras foi considerada boa pelos clientes dos dois grupos (V12, 45\% vs. 54\%, p-valor 0,13). Essa ocorrência pode representar o efeito das políticas de regulação do setor, ou mesmo de ações de marketing institucional utilizadas pelas operadoras. Quanto aos encargos financeiros necessários para trocar de operadora, eles foram avaliados como baixos por ambos os grupos (V10, 63\% vs. 67\%, p-valor 0,61) e, assim como as precauções (V11) e a reputação (V12) não apresentaram diferenças significativas. 
Tabela 01 - Imagem institucional e Fidelidade dos clientes ( $1=285$ e n2=120) e $a \leq 0.05$

\begin{tabular}{|c|c|c|c|c|c|c|c|c|c|}
\hline \multirow{2}{*}{ Variáveis } & & \multicolumn{3}{|c|}{ Pré-Pago (\%) } & \multicolumn{3}{|c|}{ Pós-Pago (\%) } & \multirow{2}{*}{\multicolumn{2}{|c|}{$\mathrm{p}$-valor $\mathrm{HO}$}} \\
\hline & & $\mathrm{D}$ & NCD & $\mathrm{C}$ & $\mathrm{D}$ & NCD & $\mathrm{C}$ & & \\
\hline Preocupa-se com os clientes. & V01 & 75 & 14 & 11 & 60 & 16 & 24 & 0,00 & RJ \\
\hline Cumpre as promessas feitas. & V02 & 66 & 15 & 19 & 55 & 14 & 31 & 0,00 & RJ \\
\hline
\end{tabular}

$\begin{array}{lllllllllll}\text { A maioria das pessoas ou das empresas gostaria de } & \text { v03 } & 64 & 18 & 18 & 53 & 17 & 30 & 0,00 & \text { RJ }\end{array}$

Eu acredito nas informações que esta operadora de telefonia móvel me fornece.

$\begin{array}{lllllllll}\text { V04 } & 63 & 15 & 22 & 47 & 13 & 40 & 0,00 & \mathrm{RJ}\end{array}$

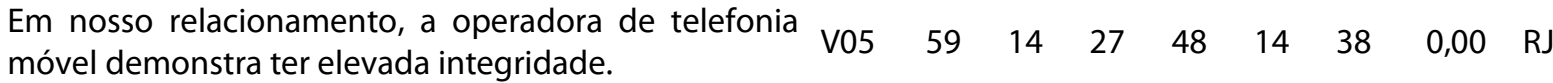

\begin{tabular}{|c|}
\hline Eu certamente recomendaria esta operadora a outras \\
\hline
\end{tabular}

Em um futuro próximo, pretendo utilizar mais os

serviços ofertados por esta operadora de telefonia V07 $\quad \begin{array}{lllllllll}68 & 13 & 19 & 60 & 6 & 34 & 0,00 & \mathrm{RJ}\end{array}$ móvel.

Mesmo que este provedor de serviços aumentasse os preços dos serviços que utilizo, ainda continuaria a ser V08 $\quad \begin{array}{llllllll}76 & 11 & 13 & 63 & 11 & 26 & 0,00 & \text { RJ }\end{array}$ seu cliente.

$\begin{array}{lllllllllll}\begin{array}{l}\text { Mudar para uma outra operadora de telefonia móvel } \\ \text { significaria muito tempo e esforço para mim. }\end{array} & \text { V09 } & 57 & 27 & 16 & 37 & 15 & 48 & 0,00 & \text { RJ }\end{array}$

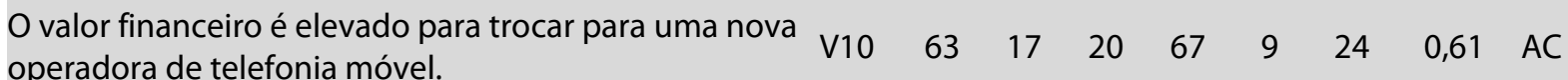
$\begin{array}{lllllllllllll}\text { É necessário tomar certas precauções com esta } \mathrm{V} 11 & 38 & 20 & 42 & 47 & 16 & 37 & 0,07 & \text { AC }\end{array}$ operadora de telefonia móvel.

$\begin{array}{llllllllll}\text { Esta operadora tem uma má reputação no mercado. } & \text { V12 } & 45 & 18 & 37 & 54 & 18 & 28 & 0,13 & \text { AC }\end{array}$ Se uma operadora de telefonia móvel concorrente

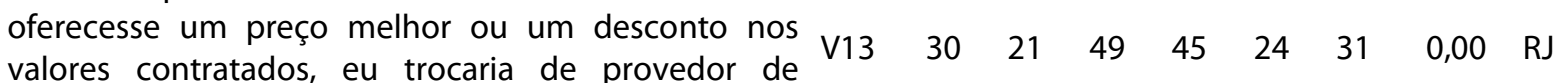
serviços.

Legenda: $\mathrm{D}=$ discordo; $\mathrm{NCD}=$ nem concordo, nem discordo; $\mathrm{C}=$ concordo.

Fonte: Pesquisa de campo (2015).

De acordo com o apresentado na Tabela 02, a maioria dos entrevistados acredita que não valeu a pena optar pela operadora utilizada, devido ao esforço para efetivar negociações e/ou contratos (V14, 62\% vs. 51\%, p-valor 0,03) ocorrendo uma insatisfação maior entre os clientes de planos pré-pagos. Os resultados obtidos nas outras variáveis não permitiram rejeitar $\mathrm{H} 0$, portanto, as diferenças estatísticas não foram significativas entre os usuários dos grupos pré-pagos e pós-pagos. Um caso detectado foi o da avaliação de compra ao longo do tempo junto à operadora, em que eles não acreditam ter resultado em uma experiência de valor (V15, 56\% vs. 52\%, p-valor 0,06). O equivalente ocorreu com a variável sobre a aceitabilidade do tempo de negociação com a operadora (V16, 51\% vs. 50\%, p-valor $0,70)$, avaliada como inaceitável para ambos. Também foi considerado um mau negócio a escolha da operadora em relação ao preço pago, nos dois grupos (V17, 46\% vs. 46\%, p-valor 0,23 ). 
Tabela 02 - Satisfação e Relacionamento ( $\mathrm{n} 1=285$ e n2=120) e $a \leq 0.05$.

\begin{tabular}{|c|c|c|c|c|c|c|c|c|c|}
\hline \multirow{2}{*}{ Variáveis } & & \multicolumn{3}{|c|}{ Pré-Pago (\%) } & \multicolumn{3}{|c|}{ Pós-Pago (\%) } & \multirow{2}{*}{$\mathrm{p}$-valor } & \multirow{2}{*}{$\mathrm{HO}$} \\
\hline & & $\mathrm{D}$ & NCD & $\mathrm{C}$ & $\mathrm{D}$ & NCD & $\mathrm{C}$ & & \\
\hline $\begin{array}{l}\text { O esforço para efetivar suas negociações e/ou } \\
\text { contrato, optar por esta operadora de telefonia } \\
\text { móvel valeu a pena. }\end{array}$ & V14 & 62 & 28 & 10 & 51 & 23 & 26 & 0,03 & RJ \\
\hline $\begin{array}{l}\text { A compra ao longo do tempo, junto a esta } \\
\text { operadora de telefonia móvel resultou em uma } \\
\text { experiência de valor. }\end{array}$ & V15 & 56 & 24 & 20 & 52 & 18 & 30 & 0,06 & $A C$ \\
\hline $\begin{array}{l}\text { O tempo necessário para efetivar os negócios } \\
\text { com esta operadora de telefonia móvel é } \\
\text { aceitável. }\end{array}$ & V16 & 51 & 20 & 29 & 50 & 24 & 26 & 0,70 & $A C$ \\
\hline $\begin{array}{l}\text { Pelo preço pago pelos serviços, a escolha por esta } \\
\text { operadora de telefonia móvel foi um bom } \\
\text { negócio. }\end{array}$ & V17 & 46 & 25 & 29 & 46 & 13 & 41 & 0,23 & $A C$ \\
\hline
\end{tabular}

Legenda: $\mathrm{D}=$ discordo; $\mathrm{NCD}=$ nem concordo, nem discordo; $\mathrm{C}=$ concordo.

Fonte: Pesquisa de campo (2015).

\section{CONSIDERAÇÕES FINAIS}

Como resultado constatou-se que, apesar da insatisfação entre os dois grupos investigados, o grupo póspago mostra insatisfação menor com os serviços de telefonia, de acordo com o teste de hipóteses para a maioria das variáveis investigadas. Provavelmente esta situação deve-se às estratégias diferenciadas, que são adotadas pelas empresas, beneficiando os clientes que oferecem a possibilidade de um vínculo mais duradouro e lucrativo. Contudo, de modo geral, a pesquisa revelou que, tanto os clientes das modalidades pré-pago, quanto pós-pago, avaliam negativamente os serviços prestados pelas operadoras de telefonia móvel, logo, os dois grupos estão insatisfeitos.

Dessa forma, os clientes atribuíram baixo valor e credibilidade aos serviços e ao relacionamento com as operadoras, pois sentem que as empresas não estão preocupadas com as suas necessidades, ou com o cumprimento das promessas. Também avaliaram negativamente a reputação e imagem organizacional, fato que limitou a recomendação da operadora para outros consumidores, diminuiu a pretensão para se adquirir serviços adicionais nas empresas, gerou um descontentamento em relação ao preço pago pelos serviços, o que prejudicou a fidelização e a retenção dos clientes.

Portanto, levando em consideração os dados apresentados - somados à relevância do setor de telefonia para a economia do país, e a quantidade de reclamações nos órgãos de defesa do consumidor - torna-se necessário que as operadoras revejam procedimentos, a fim de reforçar estratégias de marketing de relacionamento e otimizar a gestão dos serviços, para oferecer serviços com valor superior e satisfatório aos consumidores. Essas medidas possibilitam reduzir a infidelidade dos consumidores e elevam as barreiras de saída dos clientes mais lucrativos. Além disso, as empresas de telefonia podem se beneficiar com a melhora da imagem institucional, que contribui para novos negócios e proporciona lucros superiores.

\section{REFERÊNCIAS}

ABRTELECOM - ASSOCIAÇÃO BRASILEIRA DE RECURSOS EM TELECOMUNICAÇÕES. Relatório trimestral. Disponível em: <http://www.abrtelecom.com.br/>. Acesso em: 04 dez. 2015.

ADVFN - ADVANCED FINANCIAL NETWORK. Indicadores econômicos. Disponível em: <http://br.advfn.com>. Acesso em: 08 dez. 2015.

AJZENTAL, A. História do pensamento em marketing. São Paulo: Saraiva, 2010.

AMARAL, S. A.; DANTAS, E. B. Gestão da Informação Sobre a Satisfação de Clientes e Orientação para o Mercado. In: ENCONTRO DE MARKETING DA ANPAD, 3., 2008. Curitiba, 2008. Anais... Rio de Janeiro: ANPAD, 2008.

ANATEL - AGÊNCIA NACIONAL DE TELECOMUNICAÇÕES. Dados sobre telefonia móvel. Disponível em: <http://www.anatel.gov.br/>. Acesso em: 01 maio 2016. 
BOONE, L. E.; KURTZ, D. L. Marketing Contemporâneo. São Paulo: Cengage Learning, 2011.

CERVO, A. L.; BERVIAN, P. A. Metodologia científica. São Paulo: McGraw-Hill do Brasil, 1983.

COBRA, M. Administração de Marketing no Brasil. Rio de Janeiro: Elsevier, 2009.

COOPER, C. L.; ARGYRIS, C. Dicionário de administração. São Paulo: Atlas, 2003.

CORRÊA, H. L.; CAON, M. Gestão de Serviços: lucratividade por meio de operação e satisfação dos clientes. São Paulo: Atlas, 2008.

DOBNI, D.; ZINKHAN, G. M. In search of brand image: a foundation analysis. Advances in Consumer Research, v. 17, n. 1 , p. $110-120,1990$.

FITZSIMMONS, J. A.; FITZSIMMONS, M. J. Administração de serviços: operações, estratégia e tecnologia da Informação. Porto Alegre: AMGH, 2014.

GHOBADIAN, A.; SPELLER, S.; JONES, M. Service quality: concepts and models. International Journal of Quality \& Reliability Management, UK, v. 11, n. 9, p. 43-66, 1994.

GIANESI, I. G. N.; CORRÊA, H. L. Administração estratégica de serviços: operações para a satisfação do cliente. São Paulo: Atlas, 1994.

GIL, A. C. Métodos e técnicas de pesquisa social. São Paulo: Atlas, 2008.

GORDON, I. Marketing de relacionamento: estratégias, técnicas e tecnologias para conquistar clientes e mantê-los para sempre. São Paulo: Futura, 1999.

GOUVÊA, M. T. Um Modelo para Fidelização em Comunidades de Prática. 2005. 199 f. Dissertação (Mestrado em Informática) - Instituto de Matemática, Núcleo de Computação Eletrônica, Universidade Federal do Rio de Janeiro, Rio de Janeiro.

GRÖNROOS, C. Value-Driven Relational Marketing: from products to resources and competencies. Journal of Marketing Management, v. 13, n. 5, p. 407-419, 1997.

HOFFMAN, K. D. et al. Princípios de Marketing de Serviços. São Paulo: Cengage Learning, 2009.

HOOLEY, G.; PIERCY, N.F.; NICOULAND, B. Estratégia de marketing e posicionamento competitivo. São Paulo: Pearson Prentice Hall, 2011.

IBGE - INSTITUTO BRASILEIRO DE GEOGRAFIA E ESTATÍSTICA. Pesquisa anual dos serviços. Disponível em: <http://www.ibge.gov.br/>. Acesso em: 07 dez. 2015.

JOHNSTON, R. The determinants of service quality: satisfiers and dissatisfiers. International Journal of Service Industry Management, v. 6, n. 5, p. 53-71, 1995.

KOTLER, P.; HAYES, T.; BLOOM, P. N. Marketing de Serviços Profissionais: estratégias inovadoras para impulsionar sua atividade, sua imagem e seus lucros. São Paulo: Manole, 2002.

KOTLER, P.; KELLER, K. L. Administração de Marketing. São Paulo: Pearson Prentice Hall, 2006.

LAS CASAS, A. L. Novos rumos do marketing. São Paulo: Atlas, 2001.

LOVELOCK, C.; WRIGHT, L. Serviços: marketing e gestão. São Paulo: Saraiva, 2003.

MATTOS, C.A.C. et al. A satisfação do cliente-usuário com os call centers de operadoras de telefonia celular: uma investigação em Belém do Pará. Perspectivas Contemporâneas, v. 8, n. 2, p. 43-59, jul./dez. 2013. Disponível em:<http://revista.grupointegrado.br/revista/index.php/perspectivascontemporaneas/article/view/1128>. Acesso em: 15 mar. 2016. 
MATTOS, C.A.C. et al. Contexto de trabalho: uma investigação entre professores e técnicos administrativos de uma instituição federal de ensino superior. Revista de Estudos Sociais, v. 17, n. 33, p. 72-91, 2015. Disponível em: <http://periodicoscientificos.ufmt.br/index.php/res/article/view/2299.> Acesso em: 10 maio 2015.

MCKENNA, R. Marketing de Relacionamento: estratégias bem sucedidas para a era do cliente. Rio de Janeiro: Elsevier, 1997.

MONTEIRO, M. C. W. Marketing de Relacionamento: proposta de um plano de marketing de relacionamento para a genyus baterias. 2003. 147 f. Dissertação (Mestrado) - Escola Brasileira de Administração Pública e de Empresas, Centro de Formação Acadêmica e Pesquisa, Rio de Janeiro. Disponível em: <https://bibliotecadigital.fgv.br/dspace/handle/10438/3700. > Acesso em: 30 abr. 2016

NACHAR, N. The Mann-Whitney U: a test for assessing whether two independent samples come from the same distribution. Tutorials in Quantitative Methods for Psychology, v. 04, p. 13-20, 2008.

NESPOLO, D. Relação entre valor percebido, reputação, confiança e custos de troca como determinantes da retenção de clientes no contexto de serviços de telefonia móvel. 2014. 107 f. Dissertação (Mestrado) - Programa de Pós-Graduação em Administração, Universidade de Caxias do Sul, Caxias do Sul. Disponível em: <https://repositorio.ucs.br/xmlui/handle/11338/923. > Acesso em: 28 abr. 2016

NÓBREGA, K. Falando de serviços: um guia para compreender e melhorar os serviços em empresas e organizações. São Paulo: Atlas, 2013.

NOKIA-SIEMENS NETWORKS. Estudo de Aquisição e Retenção 2014 da Nokia Siemens Networks. Disponível em: <www.telebrasil.org.br>. Acesso em: 07 dez. 2015

OBOREH, J. S.; OGECHUKWU, A. D.; FRANCIS, U. G. Relationship Marketing as an Effective Strategy by lgbo Managed SME's in Nigeria. International Refereed Research Journal, v. 2, n. 2, p. 229-255, 2011.

PALADINI, E. P.; BRIDI, E. Gestão e avaliação da qualidade em serviços para organizações competitivas. São Paulo: Atlas, 2013.

PARASURAMAN, A; ZEITHAML, V. A.; BERRY, L. L. A Conceptual Model of Service Quality and Its Implications for Future Research. Journal of Marketing, New York, American Marketing Association, v. 49, p. 41-50, Fall 1985.

PINHEIRO, R. M. et al. Comportamento do consumidor e pesquisa de mercado. Rio de Janeiro: FGV, 2009.

PORTER, M. Competição. São Paulo: Campus, 2009.

SENACON - SECRETARIA NACIONAL DO CONSUMIDOR. Balanço - consumidor. Disponível em: <https://www.consumidor.gov.br/pages/publicacao/externo/>. [2015]. Acesso em: 10 maio 2016.

SHETH, J. N. New determinants of competitive structures in industrial markets: In: SPEKMAN, R. E.; WILSON, D. T. (Org.). A Strategic Approach to Business Markets. Chicago: American Marketing Association, 1985. p. 1-8.

Disponível em:

<https://www.researchgate.net/publication/237053537_New_Determinants_of_Competitive_Structures_in_Indust rial_Markets>. Acesso em: 15 mar. 2016.

TAVAKOL, M.; DENNICK, R. Making sense of Cronbach's alpha. International Journal of Medical Education, n. 2, p. 53-55, 2011.

TAVARES, M. C. A força da marca: como construir e manter marcas fortes. São Paulo: Harbra, 1998.

TELEBRASIL - ASSOCIAÇÃO BRASILEIRA DE TELECOMUNICAÇÕES. O Desempenho do Setor de Telecomunicações no Brasil. Séries Temporais, 2014. Disponível em:< www.telebrasil.org.br>. Acesso em: 07 dez. 2015

WARD, T.; DAGGER, T. The complexity of Relationship Marketing for Service Customers. Journal of Services Marketing, v. 21, n. 4, p. 281-290, 2007.

ZEITHAML, V.A.; BITNER, M. J.; GREMLER, D. D. Marketing de Serviços: a empresa com foco no cliente. Porto Alegre: AMGH Editora Ltda., 2014. 


\section{APÊNDICE A - QUESTIONÁRIO DE PESQUISA}

Este questionário é o instrumento de coleta de dados para pesquisa de trabalho de
conclusão do curso de Bacharelado em Administração, realizado na Universidade Federal do
Pará. Esta pesquisa tem como objetivo analisar o desempenho das operadoras de telefonia
móvel quanto à satisfação, imagem institucional, fidelidade e relacionamento, avaliados
pelos clientes usuários dos planos pré-pagos e pós-pagos. A finalidade deste estudo é
exclusivamente acadêmica. As respostas serão tratadas de forma confidencial e os dados
serão relatados apenas de forma agregada. Todas as informações serão codificadas e as
identidades dos entrevistados permanecerão anônimas.
Obrigado pela participação!

\section{Identificação}

1 - Sexo: $F($ ) $M()$

2 - Idade anos

3 - Qual a modalidade do serviço de telefonia que você utiliza? ( ) Pré-pago ( ) Pós-pago

4 - Assinale abaixo a operadora de telefonia móvel que você mais utiliza, ou seja, aquela que você considera como sendo a sua principal: ( ) Oi ( ) Tim ( ) Vivo ( ) Claro ( ) Outro, qual?

5. Tempo como cliente ou de contrato com a operadora: anos

6 - Utilizas o serviço de Internet disponibilizado pela operadora? ( ) Sim ( ) Não

7 - Utilizas, também, outra(s) operadora(s) de telefonia móvel? ( ) Sim ( ) Não

8 - Caso tenhas respondido "Sim", na questão anterior , qual seria esta "outra" operadora ? ( ) Oi ( ) Tim ( ) Vivo ( ) Claro ( ) Outro, qual? 


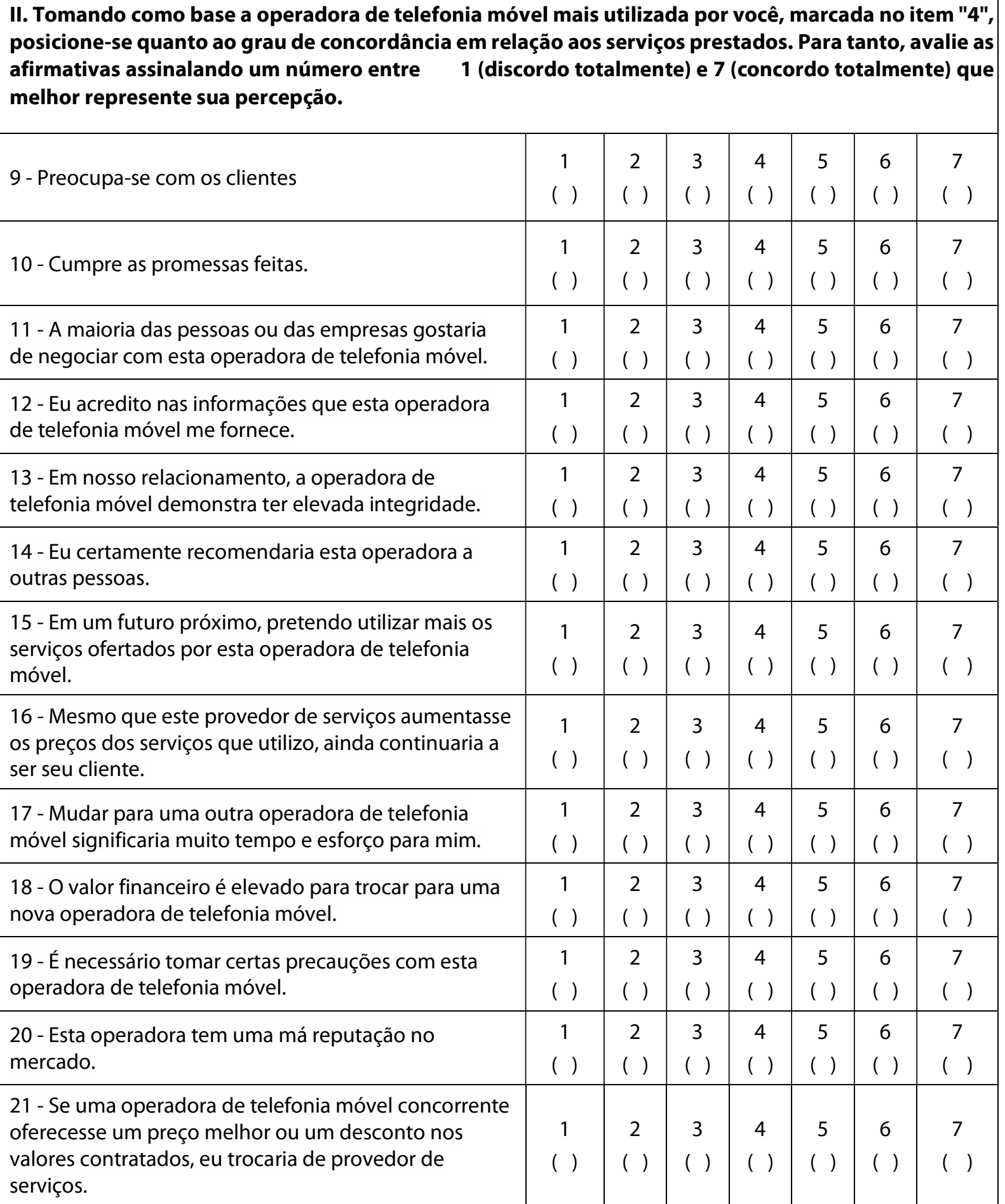

